\title{
"The reaction of Asian-Pacific investment company returns to U.S. equity returns"
}

\begin{tabular}{|c|c|c|}
\hline AUTHORS & \multicolumn{2}{|l|}{$\begin{array}{l}\text { Earl D. Benson (D) } \\
\text { Sophie X. Kong (i) }\end{array}$} \\
\hline ARTICLE INFO & \multicolumn{2}{|c|}{$\begin{array}{l}\text { Earl D. Benson and Sophie X. Kong (2021). The reaction of Asian-Pacific } \\
\text { investment company returns to U.S. equity returns. Investment Management and } \\
\text { Financial Innovations, 18(2), 209-222. doi:10.21511/imfi.18(2).2021.17 }\end{array}$} \\
\hline DOI & \multicolumn{2}{|c|}{ http://dx.doi.org/10.21511/imfi.18(2).2021.17 } \\
\hline RELEASED ON & \multicolumn{2}{|l|}{ Monday, 31 May 2021} \\
\hline RECEIVED ON & \multicolumn{2}{|l|}{ Tuesday, 06 April 2021} \\
\hline ACCEPTED ON & \multicolumn{2}{|l|}{ Wednesday, 05 May 2021} \\
\hline LICENSE & \multicolumn{2}{|c|}{$\begin{array}{l}\text { This work is licensed under a Creative Commons Attribution } 4.0 \text { International } \\
\text { License }\end{array}$} \\
\hline JOURNAL & \multicolumn{2}{|c|}{ "Investment Management and Financial Innovations" } \\
\hline ISSN PRINT & \multicolumn{2}{|l|}{$1810-4967$} \\
\hline ISSN ONLINE & \multicolumn{2}{|l|}{$1812-9358$} \\
\hline PUBLISHER & \multicolumn{2}{|c|}{ LLC "Consulting Publishing Company "Business Perspectives" } \\
\hline FOUNDER & \multicolumn{2}{|c|}{ LLC "Consulting Publishing Company "Business Perspectives" } \\
\hline$\sigma^{\circ}$ & 15 & ニ泣 \\
\hline NUMBER OF REFERENCES & NUMBER OF FIGURES & NUMBER OF TABLES \\
\hline 18 & 0 & 5 \\
\hline
\end{tabular}

(c) The author(s) 2021. This publication is an open access article. 


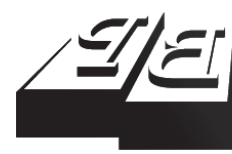

BUSINESS PERSPECTIVES

(O)

LLC "CPC "Business Perspectives" Hryhorii Skovoroda lane, 10 Sumy, 40022, Ukraine www.businessperspectives.org
Received on: $6^{\text {th }}$ of April, 2021 Accepted on: $5^{\text {th }}$ of May, 2021 Published on: $31^{\text {st }}$ of May, 2021

๑) Earl Benson, Sophie Kong, 2021

Earl Benson, Ph.D., Professor of Finance, College of Business and Economics, Finance \& Marketing Department, Western Washington University, USA. (Corresponding author)

Sophie Kong, Ph.D., Professor of Finance, College of Business and Economics, Finance \& Marketing Department, Western Washington University, USA.

\section{THE REACTION OF ASIAN-PACIFIC INVESTMENT COMPANY RETURNS TO U.S. EQUITY RETURNS}

\begin{abstract}
This study is relevant to investors who wish to diversify their investment portfolio by investing in U.S.-based investment companies that invest in specific Pacific Basin countries to better understand the diversification benefits of such investments. The purpose is to examine the daily returns of selected U.S.-based, country-focused (Pacific Basin) investment companies to see if those returns accurately reflect the changes of the equity indices of the corresponding Pacific Basin market on the following trading day. The method used is that the reactions of daily investment company returns compared to U.S. market daily returns are examined for Japan, South Korea, and Australia for the period 2006-2010. These return reactions are compared to the home-country returns. Next, for the period from 2011 to 2015, the examination is broadened to include U.S. based investment companies that invest in Taiwan, Singapore, China, and Indonesia. The results show that investment company share prices on "day t" tend to overreact to changes in the S\&P 500 on "day $t$ ", relative to "day $t+1$ " changes in the corresponding Pacific Basin market index - often by more than $100 \%$. Finally, the study shows that on "day $t+1$ " these investment company share prices exhibit a reversal. These findings indicate that the diversification benefits of investing in these Pacific Basin investment companies are reduced due to this increased volatility. S\&P 500 returns are accompanied by significantly larger returns on the Pacific Basin investment company shares than are actually realized in the home country on the following day, suggesting that the diversification benefits are not being fully realized.
\end{abstract}

\section{Keywords international finance, portfolio diversification, mutual} funds, ETFs, Pacific Basin

\section{JEL Classification G11, G15, F21}

\section{INTRODUCTION}

International diversification is one of the most important ways that asset managers and individuals can lower the risk of an investment portfolio. International diversification can be achieved by investing directly in the securities of companies based outside of the investor's home country or by investing in an investment company (either domestic or foreign) that invests in a portfolio of assets of companies that are based outside of the investor's home country. As finance students are well-aware, the risk of a portfolio can be reduced more quickly (as assets are added to the portfolio) if new assets have lower correlations of returns with the existing portfolio. Thus, those seeking to diversify internationally will seek "foreign" assets that have low correlations with their domestic portfolio so they can reduce the overall volatility of their portfolio.

For many investors, adding assets from the Asia-Pacific region may be a successful strategy for a part of their international diversification efforts. This must be done carefully, however, because the correlations of returns of one country's assets with those of other countries can vary greatly both from country to country and for a given country over time. Studies by Benson and Kong $(2015,2019)$ show that the correlation of the U.S. market (using the S\&P 500 as a proxy) with in- 
dividual markets in the Asia-Pacific region varies greatly across countries and across time. They also found that the Asia-Pacific market returns are strongly influenced by the returns of the S\&P 500 index, and that the influence is asymmetrical, with negative changes in the S\&P 500 having a far greater influence on Asia-Pacific market returns than do positive changes. These influences were greater when looking at the markets of more developed Asia-Pacific countries (such as Japan, Hong Kong, and South Korea) compared to the markets of less developed countries (like Malaysia and Thailand).

Over the past 25 to 35 years, many investment companies that are based in the U.S. have been created to invest in the assets of a single country. These investment companies include exchange-traded funds (ETFs), closed-end funds (CEFs), and open-end (or mutual) funds (OEFs). Since investing in "country-focused" investment companies is a popular strategy used by investors to diversify internationally, it is important to see if the returns of these investment companies track closely to the returns of the overall market of the country in which they invest their assets. To this point, this study examines daily returns of selected U.S.-based, country-focused (Pacific Basin) investment companies to see if those returns accurately reflect the changes of the equity indices of the corresponding Pacific Basin market on the following trading day. ${ }^{1}$ If the returns of these investment company shares do not track well with the home country markets (for example, if they are much more volatile), then diversification benefits may be reduced or nullified. On the other hand, if there are unexpected patterns in the correlations, diversification benefits may be preserved by adjusting for any documented "abnormal" patterns or correlations.

The findings suggest that the returns of the investment companies, for a given change in the S\&P 500 index, "overreact" relative to the actual change that subsequently occurs in the Pacific Basin market and that this overreaction is reversed on the next trading day. This study uses a sample of Pacific Basin countries and U.S.-based, country-focused investment companies (ETFs, CEFs, and OEFs) that have not been used in previous studies. In addition, the study uses two separate time periods for analysis, including both 2006 to 2010 and 2011 to 2015, to show that the results are not time-period specific.

\section{LITERATURE REVIEW}

The literature that is directly relevant to this study includes studies that have examined U.S.-Asian equity market linkages and studies that have examined country-specific investment vehicles offered by investment companies. There have been numerous studies over the past 30 years of U.S.-Asian equity market linkages. Early studies focused on U.S. linkages with Japan, including Becker et al. (1990), Lin et al. (1991), Becker et al. (1992), and Koutmos and Booth (1995). These studies found significant influences in both directions, and Koutmos and Booth (1995) found that negative price changes led to two to three times the price volatility in the next market compared to the impact of positive price changes.

Recognizing the significance of the Japanese market, other researchers set out to inquire whether the Japanese market has an influence on other
Asian markets that is comparable to the impact of the US market. Many of these studies support the dominance of the US market. Cheung and Mak (1992) looked at the U.S. and Japanese market impacts on eight other Asian markets, finding that the U.S. market impacts were more dominant. Further, Wei et al. (1995) and Liu and Pan (1997) both documented similar findings to those of Cheung and Mak (1992) confirming that compared to the Japanese market, the U.S. market has more influence on other Asian markets. Wei et al. (1995) included two Asian markets (Taiwan and Hong Kong), and Liu and Pan (1997) covered four Asian markets (Taiwan, Hong Kong, Singapore, and Thailand). Dekker et al. (2001) found that U.S. markets have a strong influence on all Asian-Pacific markets except Taiwan. Cheng and Glascock (2006) found that the influence of U.S. markets on Asian markets (and the co-movement among markets) increased after the Asian financial crisis in July 1997.

1 For a description and analysis of Pacific Basin ETFs (those that are the product of Asian-based investment companies and listed on Pacific Basin stock exchanges), see Marszk et al. (2019), in which they review the development of ETFs over the 2004-2017 period. 
Other studies have examined the underlying correlation between markets due to its importance in designing a diversification strategy. It has been documented that such correlations can be dynamic over time and differ greatly between different sets of countries. Kolluri et al. (2014) examined the impact of U.S. and Japanese equity markets on nine other Asian markets from 1993 to 2008 and found that market correlations are stronger when market prices fall (compared to when they rise). In a study of the correlations and covariances of Asian-Pacific equity markets with the U.S. market, Benson and Kong (2015) show that they vary significantly over time in individual markets and vary greatly across different Asian markets. Furthermore, Benson and Kong (2019) show that the "betas" of individual Asian markets (using the S\&P 500 as the market index) are not stable over time and are higher for developed economies than for developing ones. They also show that the Asian market reactions to U.S. market movements are asymmetrical where reactions to negative U.S. returns are far stronger than the reaction to positive changes.

The use of country-specific investment vehicles is one of the most convenient ways to design and implement a diversification strategy. While country-focused CEFs have been around since the late 1980s, country-focused ETFs just began trading in the late 1990s and early 2000s. Because of the availability of this new data, several recent studies have examined the reaction of these ETFs and CEFs to general market movements. Pennathur et al. (2002) find that both ETFs and CEFs with an international focus are quite sensitive to U.S. market returns. Jares and Lavin (2004) found that for the period from 1996 to 2001, the prices of ETFs for Japan and Hong Kong did not respond quickly to changes in discounts and premiums. This led to trading opportunities that could have provided significant excess returns. These studies also serve to alert researchers about potential pitfalls in such strategies.

The principal peril of using country-specific investment vehicles to gain exposure to foreign markets lies in the unsteady tracking ability of such vehicles. The fact that these vehicles are traded outside the home countries and may respond or track other factors in the trading coun- try is disturbing. Using data from 2000 to 2004, Hughen and Mathew (2009) compare ETF and CEF returns to their underlying net asset values (NAVs). They include 16 ETFs and 19 CEFs that invest in foreign equities. They find that ETF returns are more closely related to NAV returns than are CEF returns, and state that: “...prices of most of the CEFs do not quickly reflect changes in NAV..." (p. 46). Further, they find that while both ETF and CEF returns underreact to NAV changes, that both overreact to changes in the S\&P 500 returns. They state that: "...more of the ETFs overreact to domestic stock market returns than CEFs." (p. 46) In addition, they find that there is a reversal effect in which the returns of 94\% of ETFs and two-thirds of CEFs "...have a negative relation with either the one-day or twoday lagged domestic returns." (p. 49). Levy and Lieberman (2013) use a sample of U.S.-based, country-focused ETFs that invest in European and Pacific Basin equities and find that "...ETF prices overreact to US market returns during non-synchronous trading hours." (p. 1413). During synchronized trading hours, ETF prices move with the under-lying portfolio value, but when the underlying market is closed, the ETF trades with the domestic market. Levy and Lieberman (2013, p. 1416) state that when the foreign market is closed that: ETF prices are largely driven by the S\&P 500 index with little adjustment to currency effects or any lagged premiums and discounts. The effect the S\&P 500 index has on ETF intraday returns exceeds that which it has on the underlying indices, indicating an overreaction to the US market. This overreaction is then corrected for at the opening of the following US trading day.

The intension of this study is to build upon previous research by examining the behavior of a group of Asian-Pacific investment companies traded in the US. The aim is to uncover and verify any potential bias in the tracking capacity of these investment companies. The research questions focus on whether these country-specific investment companies are closely tracking the underlying markets as opposed to the market where they are traded. In addition, if any abnormality is detected, such as over- or under-reaction, the intension is to document the pattern and attempt to assess the scope of such irregularities. 


\section{METHODOLOGY, DATA AND HYPOTHESES}

This paper investigates daily returns of selected U.S.-based, Pacific Basin country-focused investment companies on day " $t$ " relative to the returns earned in the corresponding Pacific Basin market the next day (day " $t+1$ "). Reactions of investment company share values relative to the S\&P 500 index returns (day " $t$ ") are compared to the reactions of the "home-country" index relative to the S\&P 500 index returns (day " $t+1$ "). In short, the returns of selected U.S.-based, Pacific Basin country-focused investment companies are examined to see if these returns accurately reflect the changes of the equity indices of the corresponding Pacific Basin markets the next day. If not, the price movement of the U.S.-based, Pacific Basin country-focused investment companies is further examined to see if there is any additional adjustment in the investment company shares on day " $t+1$ " in the U.S. market.

To investigate these investment company share price reactions, two hypotheses are tested:

H1: The returns on day " $t$ " for selected U.S.based, Pacific Basin country-focused investment companies closely track (or reflect) the returns earned on the corresponding Pacific Basin markets the next day (day " $t+1$ ").

H2: The returns on day " $t+1$ " for selected U.S.based, Pacific Basin country-focused investment companies do not reflect the difference in their day " $t$ " returns minus the returns earned on the corresponding Pacific Basin market on day " $t+1$. ."

To test Hypothesis 1, the focus in the empirical section is on regression analysis where the country-focused investment company returns on day " $t$ " are examined as a function of 1) U.S. market returns on day " $t$ " and 2) the returns of the same country's market index for day " $t$." In functional form the model is: Country-based Investment Company Return $_{t}=f\left(\mathrm{~S} \& \mathrm{P} 500\right.$ Return $_{\mathrm{t}}$, Same Country Index Return $_{t}$ ). These results are compared to a regression of the country's market index return for day " $t+1$ " as a function of U.S. market returns on day " $t$." For Hypothesis 2, another term is added to the above model, so in functional form it looks like: Country-based Investment Company Return ${ }_{t+1}=f$ (S\&P 500 Return $_{t+1}$, Same Country Index Return ${ }_{t+1}$, Country-based Investment Company Return ${ }_{t}-$ Same Country Index Return ${ }_{t+1}$ ).

This study uses data from the "historical price" series that is available on the Yahoo Finance website. The U.S.-based ETFs, CEFs, and OEFs and the Asia Pacific indices chosen for analysis are available for free on Yahoo! Finance. Daily closing values were collected for each investment company and country index for the years 2006 through 2015. The investment company and S\&P 500 daily values are in U.S. dollars. The country index returns are based on each country's local currency, so currency exchange rates are not included in the return calculations for those indices. (Research by Panton et al. (1976), Hughen and Mathew (2009), and Levy and Lieberman (2013) suggests that the inclusion of currency changes has a little impact on daily and weekly returns.) The adjusted prices given in Yahoo are used to calculate daily returns for investment companies. Since this data source includes only the open and closing values, not hourly data, intraday returns cannot be analyzed.

Daily returns (calculated as $\left(P_{t}-P_{t-1}\right) / P_{t-1}$, using the adjusted prices given on Yahoo! Finance) on each foreign index and U.S. investment company are matched with the corresponding daily returns on the S\&P 500 index. The estimates in Table A1 (see Appendix) use only those S\&P 500 returns that have a value equal to or less than -1 percent. The paper focuses on these large negative daily changes because past research shows that asset values react much more strongly to negative changes. Plus, traders and asset managers are more likely to react to large U.S. market daily changes but would ignore smaller day-to-day fluctuations that are more "noise" than they are meaningful market moves. For the 2006-2010 period this resulted in a sample of about 270 to 275 days for $-1 \%$ or lower returns out of a total of 1,260 trading days. Using the 2011-2015 period this resulted in a sample of about 125 to 135 days for $-1 \%$ or lower returns.

The trading days for the S\&P 500 index were matched with each foreign index used in the study. If one of the large negative moves in the S\&P 500 occurred on the day before the foreign market 
had a holiday, the observation was deleted from the sample. Since different countries have different sets of market holidays, the sample sizes used for different country-based investment companies are slightly different.

To help assure that the results are not time-period specific, the analysis is done using two separate periods, 2006-2010 and 2011-2015. The hypotheses are first tested using the data for 2006-2010, using Japan, South Korea, and Australia as countries of interest. Next, the data for 2011-2015 is used with an expanded set of countries, to see if the results from the first period are confirmed in the next period.

\section{EMPIRICAL FINDINGS}

This section examines the return reactions of selected U.S.-based, "country-focused" ETFs, CEFs, and OEFs, to large negative changes in the S\&P 500 index; and compares these returns to the returns of the foreign index return representing that country. Specifically, what is tested is whether the trading prices in the U.S. fully adjust on day " $\mathrm{t}$ " to the actual change on day " $t+1$ " in the Pacific Basin market. To examine this question, investment companies that invest in Japanese, South Korean, and Australian stocks over the 2006 to 2010 period are used for the investigation. In the first tests Japan is selected as a country of interest because the Nikkei 225 reacts strongly to movements in the S\&P 500 (Benson \& Kong, 2019) and because several investment companies have existed since the early 1990s that invest exclusively in Japanese equities. The investment companies chosen are a Japanese equity ETF, iShares MSCI Japan (EWJ); a CEF, Japan Equity Fund (JEQ); and an OEF, the Fidelity Japan Fund (FJPNX).

Table 1 shows how the returns of these three Japanese equity investment companies behave on days when the S\&P 500 fell by one (1) percent or more over the 2006-2010 period. The table shows that the Nikkei 225 on day " $t+1$ " changes, on average, by 0.75 of the S\&P 500 return on day " $t$ " when the S\&P 500 return was $-1 \%$ or lower. The estimated equation is:

$$
N 225_{t+1}=a_{i}+b_{i}\left(S \& P 500_{t}\right) .
$$

Panel A of Table 1 shows the determinants of the returns of the iShares MSCI Japan ETF (trading

Table 1. Regression estimates for the determinants of Japanese equity investment company returns using daily returns for 2006-2010 for the days when the S\&P 500 daily return was $-1 \%$ or lower

\begin{tabular}{|c|c|c|c|c|c|c|c|c|}
\hline \multicolumn{9}{|c|}{ Index or Investment Co. Return } \\
\hline Dependent variable & \multicolumn{8}{|c|}{ Explanatory variables (coefficients and t-statistics) } \\
\hline \multirow{2}{*}{$N 225_{t+1}$} & S\&P $500_{t}$ & t-stat & & & & & $R^{2}$ & $\mathbf{N}$ \\
\hline & 0.75 & 7.97 & & & & & 0.23 & 209 \\
\hline \multicolumn{9}{|c|}{ Panel A: Exchange-traded Fund (iShares MSCI Japan) } \\
\hline \multirow{2}{*}{$\mathrm{EWJ}_{t}$} & $S \& P 500_{t}$ & t-stat & $\mathbf{N} 225_{t}$ & t-stat & & & & \\
\hline & 0.72 & 12.32 & 0.22 & 5.92 & & & 0.52 & 204 \\
\hline \multirow{2}{*}{$\mathrm{EWJ}_{t+1}$} & S\&P $500_{t+1}$ & t-stat & $\mathbf{N} 225_{t+1}$ & t-stat & $E W J_{t}-N 225_{t+1}$ & t-stat & & \\
\hline & 0.67 & 16.42 & 0.07 & 1.10 & -0.30 & -5.30 & 0.70 & 204 \\
\hline \multicolumn{9}{|c|}{ Panel B: Closed-end Fund (Japan Equity Fund) } \\
\hline \multirow{2}{*}{$\mathrm{JEQ}_{t}$} & S\&P $500_{t}$ & t-stat & N225 & t-stat & & & & \\
\hline & 0.93 & 14.27 & -0.23 & -5.66 & & & 0.51 & 204 \\
\hline \multirow{2}{*}{$\mathrm{JEQ}_{t+1}$} & S\&P $500_{t+1}$ & t-stat & $\mathbf{N} 225_{t+1}$ & t-stat & $\mathrm{JEQ}_{t}-\mathrm{N} 225_{\mathrm{t}+1}$ & t-stat & & \\
\hline & 0.67 & 14.69 & 0.26 & 3.47 & -0.13 & -2.05 & 0.65 & 204 \\
\hline \multicolumn{9}{|c|}{ Panel C: Open-end (Mutual) Fund (Fidelity Japan Fund) } \\
\hline \multirow{2}{*}{ FJPNX $_{t}$} & $S \& P 500_{t}$ & t-stat & $\mathrm{N}^{225_{\mathrm{t}}}$ & t-stat & & & & \\
\hline & 0.70 & 12.40 & 0.38 & 10.74 & & & 0.62 & 204 \\
\hline \multirow{2}{*}{ FJPNX $_{t+1}$} & S\&P $500_{t+1}$ & t-stat & $N 225_{t+1}$ & t-stat & FJPNX $_{t}-\mathrm{N}^{225_{t+1}}$ & t-stat & & \\
\hline & 0.65 & 16.90 & 0.27 & 4.77 & -0.19 & -3.80 & 0.73 & 204 \\
\hline
\end{tabular}


symbol EWJ). The first regression equation in Panel A shows the estimation for:

$$
E W J_{t}=a_{i}+b_{i}\left(S \& P 500_{t}\right)+c_{i}\left(N 225_{t}\right) \text {. }
$$

The regression coefficient (or beta) of EWJ relative to the $S \& P 500$ is 0.72 . This is slightly lower than the regression coefficient for the Nikkei 255 $(N 225)$ of 0.75 on day " $t+1$." Thus, the reaction of $E W J$ to the $S \& P 500$ movement is, on average, weaker than the subsequent movement of the N225 index a few hours later (on calendar day " $t+1$ "). The inclusion of the Nikkei 225 (which closed a few hours earlier) adds to the explanatory power of the model, having a statistically significant coefficient of 0.22 . However, the U.S. market returns clearly dominate as the main explanatory variable. These findings are consistent with previous studies documenting that ETFs are more sensitive to US market movements than to their corresponding foreign home market movements (Pennathur et al., 2002; Hughen \& Mathew, 2009; Levy \& Lieberman, 2013).

The second regression estimate in Panel A is for the equation:

$$
\begin{aligned}
& E W J_{t+1}=a_{i}+b_{i}\left(S \& P 500_{t+1}\right)+ \\
& +c_{i}\left(N 225_{t+1}\right)+d_{i}\left(E W J_{t}-N 225_{t+1}\right) .
\end{aligned}
$$

This equation is an estimate for the determinants of the return on $E W J$ on the day following the large (1 percent or greater) drop in the $S \& P 500$. It shows that the return of $E W J_{t+1}$ is affected by the $S \& P 500_{t+1}$ return, the $N 225_{t+1}$ return, and the difference in returns $E W J_{t}-N 225_{t+1}$. The coefficient representing the impact of the $S \& P 500$ on $E W J$ is slightly lower (0.67) than the previous estimates. The $N 225$ has an insignificant impact. The difference, $E W J_{t}-N 225_{t+1}$, is the return on EWJ on day " $t$ " minus the return on $N 225$ a few hours later; so, we are looking at the estimated adjustment made in the exchange-traded fund minus the actual change that was made in the N225 index. If the EWJ over-adjusted on day " $t$ ", we might see a reversal on the next day (day " $t+1$ "). This is exactly what the statistically significant coefficient of -0.30 indicates. Panels $\mathrm{B}$ and $\mathrm{C}$ of Table 1 show similar results for the CEF, the Japan Equity Fund, and the OEF, the Fidelity Japan Fund, respectively. The CEF results show in the first equation of Panel B that there is a much stronger reaction of the JEQ fund to the $S \& P 500$ return on the day of the large negative change (compared to the next day reaction of the N225), but a significant negative reaction to the N225 return for that day. The second equation shows a reversal similar to the ETF results in Panel A. The first equation for the OEF results in Panel C show a smaller reaction to the $S \& P 500$ returns, than are the reactions in Panels A and B for the ETF and CEF. The second equation shows a reversal on the next day. For both the CEF and OEF, the coefficients of -0.13 and -0.18 suggest a reversal.

Next, investment companies that invest in South Korea are examined. For this analysis, the investment companies chosen are a South Korean equity ETF, iShares MSCI S Korea (EWY); a CEF, the Korea Fund (KF); and an OEF, the Matthews Korea Fund (MAKOX). Table 2 reports the findings and shows that the KS11 index on day " $t+1$ " changes, on average, by 0.48 of the S\&P 500 return on day " $t$ " when the $S \& P 500$ return was $-1 \%$ or lower. Panel A of Table 2 shows the determinants of the returns of the iShares MSCI S Korea exchange-traded fund (EWY). The first estimate shows that the coefficient of EWY relative to the $S \& P 500$ is 1.12 , more than double the reaction of the KS11 index a few hours later. Also, compared to the regression coefficient for the iShares MSCI Japan Fund in Table 1 of 0.72 , this coefficient of 1.12 is far higher. The impact of the return of KS11 on day " $t$ " (representing the Korea Composite trading from a few hours earlier) adds significantly to the explanatory power of the model, with a coefficient of 0.64 . While the U.S. market returns are the primary explanatory variable, the KS11 returns have a stronger impact than do the N225 returns in Panel A of Table 1. The second regression estimate in Panel A of Table 2 shows an estimate for the determinants of the return on EWY on the day following the large (1 percent or greater) drop in the $S \& P 500$. It shows that $E W Y_{t+1}$ is affected by S\&P $500_{t+1}, \mathrm{KS} 11_{t+1}$, and the difference $E W Y_{t}-\mathrm{KS}_{11_{t+1}}$. Similar to the discussion above for Japan, the difference, $E W Y_{t}-\mathrm{KS}_{t+1}$, is the return on EWY on day " $t$ " minus the return on KS11 a few hours later; so, we are looking at the estimated adjustment made in the exchange-traded fund minus the actual change that was made in the KS11 
Index. If the EWY over-adjusted on day " $t$ ", we might see a reversal on the next day (day " $t+1$ "). Again, this is what the statistically significant coefficient of -0.19 indicates. Panels B and C of Table 2 show similar results for the CEF, Korea Fund (KF), and the OEF, Matthews Korea Fund (MAKOX), respectively. The returns of EWY (Panel A) react somewhat more strongly to changes in the $S \& P 500$ than the returns of KF in Panel B; and the investment company with the lowest reaction is MAKOX with a coefficient relative to the $S \& P 500$ of 0.73 . However, the reactions of all three investment companies to the $S \& P 500$ returns on day " $t$ " are far stronger than the subsequent reaction on day " $t+1$ " of the KS11 index to the $S \& P 500$ index returns (where the coefficient is 0.48). Further, all three show negative and significant "reversals" on day $t+1$ (but is only significant at the $12 \%$ level for MAKOX).

It is noteworthy that the South Korean OEF in Table 2 reacts to the $S \& P 500$ negative changes in a more muted fashion than do the ETF and the CEF (with a coefficient of 0.73 versus 1.12 and 1.08). This is also true to a lesser extent in Table 1 where the Japan OEF has a coefficient of only 0.70 , compared to 0.72 and 0.93 for the ETF and CEF. OEF (or mutual fund) shares are traded at the net asset value (NAV) of the fund at the end of the trading day and for a fund that invests in Pacific Basin stocks, many of those stocks will not have traded in the previous 15 hours. (For example, the Japanese and South Korean equity markets close at $1 \mathrm{am}$ New York time.) ETFs and CEFs, on the other hand, trade at constantly changing bid and ask market prices. This suggests that the prices of these ETFs and CEFs may react more strongly to changes in the U.S. markets due to the way they are traded and priced compared to OEFs.

A third example includes investment companies that invest in Australian equities. For this analysis, the investment companies selected are an Australian equity ETF, iShares MSCI Australia (EWA), and a CEF, the Aberdeen Australia Equity Fund (IAF). (We could find no U.S.-based OEF that invests exclusively in Australian equities and for which trading data is reported on Yahoo! Finance.) Table 3 reports the findings and includes a comparison showing that the AORD index on day " $t+1$ " changes, on average, by 0.53 of the $S \& P 500$ return on day " $t$ " when the

Table 2. Regression estimates for the determinants of South Korean equity investment company returns

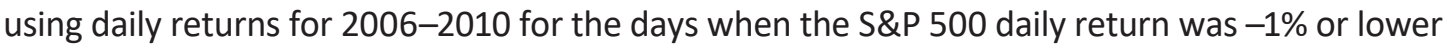

\begin{tabular}{|c|c|c|c|c|c|c|c|c|}
\hline \multicolumn{9}{|c|}{ Index or Investment Co. Return } \\
\hline $\begin{array}{l}\text { Dependent } \\
\text { variable }\end{array}$ & \multicolumn{8}{|c|}{ Explanatory variables [coefficients and t-statistics] } \\
\hline \multirow{2}{*}{$\mathrm{KS} 11_{t+1}$} & S\&P 500 & $t$-stat & & & & & $R^{2}$ & $\mathbf{N}$ \\
\hline & 0.48 & 4.44 & & & & & 0.09 & 206 \\
\hline \multicolumn{9}{|c|}{ Panel A: Exchange-traded Fund (iShares MSCI S Korea) } \\
\hline \multirow{2}{*}{$E W Y_{t}$} & $S \& P 500_{t}$ & $t$-stat & $\mathrm{KS} 11_{t}$ & $t$-stat & & & & \\
\hline & 1.12 & 15.16 & 0.64 & 11.76 & & & 0.69 & 206 \\
\hline \multirow{2}{*}{$E W Y_{t+1}$} & S\&P $500_{t+1}$ & $t$-stat & $\mathrm{KS} 1_{t+1}$ & $t$-stat & $E W Y_{t}-K S 11_{t+1}$ & $t$-stat & & \\
\hline & 1.32 & 27.00 & 0.75 & 12.26 & -0.19 & -4.47 & 0.88 & 206 \\
\hline \multicolumn{9}{|c|}{ Panel B: Closed-end Fund (Korea Fund) } \\
\hline \multirow{2}{*}{$\mathrm{KF}_{t}$} & $S \& P 500_{t}$ & $t$-stat & $\mathrm{KS} 1_{t}$ & t-stat & & & & \\
\hline & 1.08 & 12.03 & 0.57 & 8.57 & & & 0.56 & 206 \\
\hline \multirow{2}{*}{$\mathrm{KF}_{t+1}$} & S\&P $500_{t+1}$ & $t$-stat & $\mathrm{KS} 11_{t+1}$ & t-stat & $\mathrm{KF}_{t}-\mathrm{KS} 11_{t+1}$ & $t$-stat & & \\
\hline & 1.02 & 20.02 & 0.67 & 11.19 & -0.13 & -3.06 & 0.82 & 206 \\
\hline \multicolumn{9}{|c|}{ Panel C: Open-end (Mutual) Fund (Matthews Korea Fund) } \\
\hline \multirow{2}{*}{ MAKOX $_{t}$} & S\&P $500_{t}$ & t-stat & $\mathrm{KS} 1_{t}$ & t-stat & & & & \\
\hline & 0.73 & 10.76 & 0.64 & 12.69 & & & 0.62 & 206 \\
\hline \multirow{2}{*}{ MAKOX $_{t+1}$} & S\&P $500_{t+1}$ & $t$-stat & $\mathrm{KS} 1_{t+1}$ & $t$-stat & MAKOX $_{t}-\mathrm{KS} 1_{t+1}$ & $t$-stat & & \\
\hline & 0.66 & 11.88 & 0.93 & 11.64 & -0.09 & -1.57 & 0.77 & 206 \\
\hline
\end{tabular}


$S \& P 500$ return was $-1 \%$ or lower. Panel A of Table 3 shows the determinants of the returns of the iShares MSCI Australia ETF (EWA). The first regression estimate shows a coefficient (or beta) of EWA relative to the $S \& P 500$ is 1.03 , nearly double the reaction of the AORD index a few hours later. Further, this coefficient of 1.03 is of similar size to the regression coefficient for the iShares MSCI South Korea Fund in Table 2 of 1.12. In the same regression equation, the return of AORD on day " $t$ " (representing the All Ordinaries trading from a few hours earlier) also has a significant impact on EWA returns on day " $t$," but is not nearly as significant as the $S \& P 500$ returns. The second regression in Panel A shows the estimate for EWA on the day following the large drop in the $S \& P 500$. It shows that $\mathrm{EWA}_{t+1}$ is affected by S\&P $500_{t+1}, \mathrm{AORD}_{t+1}$, and the difference $\mathrm{EWA}_{t}-\mathrm{AORD1}_{t+1}$. Like the discussion above, the difference, $\mathrm{EWA}_{t}-\mathrm{AORD}_{t+1}$, is looking at the estimated adjustment made in the exchange-traded fund minus the actual change that was made in the AORD index. If the EWA over-adjusted on day " $t$ ", a reversal might be seen on the next day (day " $t+1$ "). Again, this is what the statistically significant coefficient of -0.25 indicates. Panel B of Table 3 shows similar results for the CEF, the Aberdeen Australia Equity Fund (IAF). The returns of IAF in Panel B react to changes in the S\&P 500 somewhat more than the returns of EWA (Panel A). The reactions of both investment companies to the $S \& P$
500 returns (with coefficients of 1.03 and 1.22) on day " $t$ " are far stronger than the subsequent reaction on day " $t+1$ " of the AORD index to the S\&P 500 index returns (where the coefficient is 0.53 ). While the EWA reversal term is highly significant, the IAF reversal term is significant at only the $10 \%$ level of significance.

The evidence in Tables 1, 2, and 3 suggests rejection of Hypothesis 1 that returns on selected U.S.based, Pacific Basin country-focused investment companies accurately reflect the returns earned the next day in that Pacific Basin market. In all cases for South Korea and Australia, the reaction of the investment companies to S\&P 500 changes was greater than the next day change in that Pacific Basin market. For Japan, this was true only for the CEF, while the ETF and OEF had slightly smaller reactions. While for the Japanese focused funds, the reaction is only marginally different overall, for South Korea and Australia the reaction of investment company share prices is roughly 100 percent stronger than the next day change in that Pacific Basin market, suggesting a day " $t$ " overreaction to large negative changes in the S\&P 500 index.

Hypothesis 2 is tested in the second equations in Panels A, B, and C of Tables 1, 2, and 3. The third variable in each of these equations is looking at the difference in the U.S. country-based in-

Table 3. Regression estimates for the determinants of Australian equity investment company returns using daily returns for $2006-2010$ for the days when the S\&P 500 daily return was $-1 \%$ or lower

\begin{tabular}{|c|c|c|c|c|c|c|c|c|}
\hline \multicolumn{9}{|c|}{ Index or Investment Co. Return } \\
\hline $\begin{array}{c}\text { Dependent } \\
\text { variable }\end{array}$ & \multicolumn{8}{|c|}{ Explanatory variables [coefficients and t-statistics] } \\
\hline \multirow{2}{*}{$\mathrm{AORD}_{t+1}$} & S\&P $500_{t}$ & t-stat & & & & & $R^{2}$ & $\mathbf{N}$ \\
\hline & 0.53 & 8.08 & & & & & 0.24 & 214 \\
\hline \multicolumn{9}{|c|}{ Panel A: Exchange-traded Fund (iShares MSCI Australia) } \\
\hline \multirow{2}{*}{ EWA $_{t}$} & S\&P $500_{t}$ & t-stat & AORD $_{t}$ & t-stat & & & & \\
\hline & 1.03 & 14.20 & 0.56 & 8.02 & & & 0.60 & 214 \\
\hline \multirow{2}{*}{$\mathrm{EWA}_{t+1}$} & S\&P $500_{t+1}$ & t-stat & AORD $_{t+1}$ & t-stat & $\mathrm{EWA}_{t}-\mathrm{AORD}_{t+1}$ & $t$-stat & & \\
\hline & 1.16 & 26.28 & 0.35 & 5.01 & -0.25 & -5.74 & 0.83 & 214 \\
\hline \multicolumn{9}{|c|}{ Panel B: Closed-end Fund (Aberdeen Australia Equity Fund) } \\
\hline \multirow{2}{*}{$\mathrm{IAF}_{t}$} & S\&P $500_{t}$ & $t$-stat & AORD $_{t}$ & t-stat & & & & \\
\hline & 1.22 & 12.11 & 0.84 & 8.65 & & & 0.56 & 214 \\
\hline \multirow{2}{*}{$\mathrm{IAF}_{t+1}$} & S\&P $500_{t+1}$ & t-stat & AORD $_{t+1}$ & t-stat & $\mathrm{IAF}_{t}-\mathrm{AORD}_{\mathrm{t}+1}$ & $t$-stat & & \\
\hline & 1.22 & 15.20 & 0.72 & 6.08 & -0.09 & -1.43 & 0.65 & 214 \\
\hline
\end{tabular}


vestment company return in period " $t$ " minus the same country's index return in period " $t+1$." This is the overreaction of the U.S. investment company's share price relative to what actually happened to the country's index in the hours following the close of the U.S. market. Since this variable is statistically significant and negative in virtually all the Panels' second equations in Tables 1, 2, and 3 , it suggests that Hypothesis 2 should be rejected. The Pacific Basin investment company share prices do correct on day " $t+1$ " for the overreaction on day " $t$ " to large negative changes in the S\&P 500 index.

To get an idea of the true size of the reversal, it is necessary to look at both the coefficient and the size of the variable (in this case, the size of the overreaction). From Table 1, the coefficient for the variable EWJ $-\mathrm{N}_{t} 25_{t+1}$ is -0.30 . The average value for $\mathrm{EWJ} \mathrm{t}_{t}-\mathrm{N} 225_{t+1}$ is -0.2595 percentage points. Thus, the average reversal on day " $t+1$ " is -0.30 times $-0.2595 \%$ or +0.078 percentage points. (A similar estimate for $\mathrm{JEQ}_{t}-\mathrm{N} 225_{t+1}(-0.13 \mathrm{x}-0.2223 \%)$ is only +0.029 percentage points.) This happens after every large negative change ( $1 \%$ or more) in the S\&P 500 - in 2006-2010 about 40 times each year.

Moving to the reversals shown in Table 2 for South Korea, the ETF coefficient for the variable EWY $\mathrm{KS} 1_{t+1}$ is only -0.19 . However, the average value for $\mathrm{EWY}_{t}-\mathrm{KS}_{t+1}$ is very high at -1.9672 percentage points. Therefore, the average reversal on day " $t+1$ " is -0.19 times $-1.9672 \%$ or +0.374 percentage points. For the CEF, the reversal can be calculated as -0.13 times $-1.5872 \%$ or +0.206 percentage points. Finally, looking at the ETF in Table 3, the coefficient on $\mathrm{EWA}_{t}-\mathrm{AORD}_{t+1}$, of -0.25 times the average value of $\mathrm{EWA}_{t}-\mathrm{AORD}_{t+1}$ of -1.6310 percentage points gives us an average reversal in the ETF on day " $t+1$ " of +0.408 percentage points. The average reversal for the CEF (IAF) $(-0.09 \mathrm{x}$ $-1.4137)$ is only +0.127 percentage points. From the calculations for Tables 2 and 3, the reversals for the South Korean and Australian ETFs are sizeable, and the reversals for the CEFs are only about one-half and one-third that of the ETFs, respectively.
This study now examines the subsequent five-year period - the period from 2011 to 2015 - to see if the findings from Tables 1 through 3 continue to exist in the period from 2011-2015. Two additional elements are added in this analysis. First, the subject countries are broadened to include Taiwan, Singapore, China, and Indonesia. ${ }^{2}$ Second, the reaction to changes in U.S. market returns are broadened to include not only the large negative changes but also ALL changes. Table A1 shows these results for the three countries used in Tables A1, A2, and A3 (Japan, South Korea, and Australia, respectively) plus the four newly added countries. For each country, the table shows the reaction of the country equity index (for day " $t+1$ ") in column "A" and the reaction of an ETF and a CEF (for day " $t$ ") in columns " $\mathrm{B}$ " and " $\mathrm{C}$ " to daily changes in the S\&P 500 index in period " $t . " 3$ These reactions are shown for both "all daily return changes" in the first row and for only those daily changes that are equal to or lower than $-1.0 \%$ in the following row. Looking at column " $\mathrm{A}$ ", the "beta" coefficient for the impact of the S\&P 500 for day " $t$ " on the index returns for day " $t+1$ " is generally higher for the changes that are equal to or lower than $-1.0 \%$, compared to the regression for "all changes." The exceptions are Japan and Australia. The reaction of equity markets to all daily changes in the U.S. market is strongest in Japan, with a coefficient of 0.67 , while the reaction to large negative changes is strongest in South Korea, with a coefficient of 0.68 .

Of most interest in this study is an examination of how the changes in the S\&P 500 affect U.S.-based investment company returns relative to the home market equity returns. Columns " $\mathrm{B}$ " and "C" in Table Al show that all investment company reactions are far stronger than the index reactions that occur a few hours later for all seven countries. This, again, supports the rejection of Hypothesis 1 because there appears to be a significant overreaction of the investment company share prices to the U.S. market price changes. Focusing on the reactions of ETFs to all price changes, the coefficients are all much higher than the subsequent country index returns and most are more than

2 These additional Pacific Basin countries were selected because they have an ETF and a CEF that is traded in the U.S., and their country index prices were available on Yahoo! Finance for the period of 2011-2015.

3 Mutual Funds (OEFs) are not included in these tests because most of the countries used in these tests did not have an associated OEF during the sample period that was reported in Yahoo! Finance. 
twice as high. For Australia, the ETF coefficient is 1.07 , compared to a subsequent All Ordinaries Index reaction of 0.48 . For China, the ETF coefficient is 0.93 , compared to a subsequent Shanghai Composite Index reaction of only 0.27 . The pattern is similar using large negative U.S. market price changes. For example, for Japan, the reactions (or "betas") of the Index, ETF, and CEF are 0.55, 0.84, and 0.94 , respectively. For South Korea, the values are $0.68,1.12$ and 1.01; for Australia they are 0.26, 1.22, and 0.93; and for China the values are 0.33, 0.81 , and 0.80 . Of particular note is the sizable reaction of the Australian ETF to U.S. market large negative changes, which is more than quadruple the reaction of the All-Ordinaries Index.

It is also instructive to compare the 2006 to 2010 results in Tables 1, 2, and 3 to the 2011 to 2015 results in Table A1. For Japan, the coefficient in Table A1 for the Nikkei 225 index for negative changes is 0.55 , lower than the 0.75 in Table 1 . However, the coefficients for EWJ and JEQ rise to 0.84 and 0.94 , compared to their Table 1 values of 0.72 and 0.93 , respectively. For South Korea, the coefficients in Table A1 are mixed relative to those in Table 2. Looking at the negative S\&P 500 return results, the Table A4 coefficients for KS11, EWY, and KF are $0.68,1.12$, and 1.01 , compared to $0.48,1.12$, and 1.08 in Table 2. However, the investment company reactions are still a lot larger in the 2011-2015 period than is the Korean stock index reaction. Finally, for Australia, the Table A1 coefficients for AORD, EWA, and IAF are $0.26,1.22$, and 0.93 , compared to $0.53,1.03$, and 1.22 in Table 3. So, the All Ordinaries 2011 to 2015 reaction to S\&P 500 changes shown in Table A1 falls by about half (relative to 2006 to 2010 reaction in Table 3), the exchange-traded fund (EWA) reaction increases, and the closed-end fund (IAF) reaction decreases. However, relative to the AORD coefficient of only 0.26 , the relative reactions of EWA and IAF are both higher, being about four to five times higher than the subsequent change in the index, AORD. For the remaining countries shown in Table A1 (Taiwan, Singapore, China, and Indonesia), the reactions of ETFs and CEFs to S\&P 500 returns are all much stronger than the subsequent reaction of the country index, showing a similar overreaction to those for Japanese, South Korean, and Australian funds.

These reactions of investment companies support the general results shown by Hughen and Mathew (2009) and Levy and Lieberman (2013) that country-based investment company shares overreact to changes in the S\&P 500 index. These results not only confirm the overreaction that is shown in other studies, but also demonstrate that the relationships shown in Tables 1, 2, and 3 of this study for the 2006 to 2010 period (an exceptional period that included The Great Recession) continue to exist in the 2011 to 2015 period. These findings are much more specific to individual countries and funds in these countries than any previous research study.

Using the same countries shown in Table A1, Table A2 shows what has happened to ETF and CEF daily returns the day following a large negative change in the S\&P 500 for 2011 to 2015. Here, the goal is to test Hypothesis 2 to see if the overreaction of the investment company share prices is corrected for on day " $t+1$." For Japan, South Korea, and Australia, the results are similar to the 2006 to 2010 results shown in Tables 1, 2, and 3, respectively. For all seven countries, the ETF and CEF returns show a reversal on day " $t+1$," making up for the overreaction of the funds on the previous day. All of the coefficients on the "overreaction variables" for all countries are statistically significant. This suggests that Hypothesis 2 can be rejected for the 2010 to 2015 period, and these results support the findings of Levy and Lieberman (2013) who show that the overreaction is corrected for the next trading day.

\section{CONCLUSION}

This paper looks at the reaction of the daily returns of U.S.-based investment companies (that invest in Pacific Basin equities) to large negative returns in the S\&P 500 index. More specifically, it looks at how well these Asia-Pacific investment company shares track the equity returns in the home country. The examination of investment companies that invest in Japanese, Korean, and Australian equities for the 
2006-2010 period, suggests that the prices of the investment companies on day " $t$ " overreact to the negative movement of the S\&P 500 index on day " $t$," relative to the subsequent reaction of the country index (the Nikkei 255, the Kospi Composite, and AORD) on day " $t+1$." The 2006 to 2010 results also show that the overreaction is, at least in part, corrected for on the following trading day.

Further tests were conducted for the 2011-2015 period for these three countries plus Taiwan, Singapore, China, and Indonesia. Using both large negative changes and all changes in the S\&P 500 Index, the empirical tests show that the overreaction persists. For all countries, including Japan, the reactions of ETFs and CEFs to S\&P 500 returns are all much stronger (most being about twice as high) than the subsequent reaction of the country index. In addition, the results suggest that for large negative changes in the S\&P 500, the ETFs and CEFs correct for the overreaction of day " $t$," because on day " $t+1$ " there is a reversal of the overreaction.

These findings suggest that investors in U.S.-based equity investment companies should be cognizant of the volatile nature of country-focused (Pacific Basin) investment companies. This volatility can severely reduce the diversification benefits that investors hope to achieve by investing internationally, including Asia-Pacific markets. It is at times of large declines in domestic markets, that investors hope to realize the benefits of international diversification. If, as shown in this study, share prices of country-focused investment companies react far stronger to a steep loss in the domestic equity market on "day $t$ " than do the equities in the home country on "day $t+1$ ", then the benefits of international diversification are compromised, at best, and may be completely nullified, at worst. Further research needs to be done for a larger number of countries, as data becomes available, to see 1) if this is true for Pacific Basin countries that are not included in this study, and 2) if the overreactions and subsequent reversal are exploitable by traders.

\section{AUTHOR CONTRIBUTIONS}

Conceptualization: Earl Benson, Sophie Kong.

Data Curation: Earl Benson, Sophie Kong.

Formal Analysis: Earl Benson, Sophie Kong.

Investigation: Earl Benson, Sophie Kong.

Methodology: Earl Benson, Sophie Kong.

Project Administration: Earl Benson.

Resources: Earl Benson, Sophie Kong.

Software: Earl Benson, Sophie Kong.

Supervision: Earl Benson.

Validation: Sophie Kong.

Visualization: Earl Benson, Sophie Kong.

Writing_original draft: Earl Benson.

Writing_-review \& editing: Earl Benson, Sophie Kong.

\section{REFERENCES}

1. Becker, K., Finnerty, J., \& Gupta, M. (1990). The intertemporal relation between the U.S. and Japanese stock markets. The Journal of Finance, 45(4), 1297-1306. http://dx.doi. org/10.2307/2328726

2. Becker, K., Finnerty, J., \& Tucker, A. (1992). The intraday interdependence structure between
U.S. and Japanese equity markets. The Journal of Financial Research, 15(1), 27-37. http://dx.doi. org/10.1111/j.1475-6803.1992. tb00784.x

3. Benson, E., \& Kong, S. (2015). The co-movement of U.S. equity market returns with the developed and emerging markets of Australasia and Asia. International
Journal of Business and Social Research, 5(1), 102-117. https:// doi.org/10.18533/ijbsr.v5i1.503

4. Benson, E., \& Kong, S. (2019). The influence of U.S. equity returns on Asia-Pacific equity markets. Investment Management and Financial Innovation, 16(4), 4660. http://dx.doi.org/10.21511/ imfi.16(4).2019.05 
5. Cheng, H., \& Glascock, J. (2006). Stock market linkages before and after the Asian financial crisis: Evidence from three greater China economic area stock markets and the US. Review of Asian-Pacific Financial Markets and Policies, 9(2), 297-315. http://dx.doi. org/10.1142/S0219091506000732

6. Cheung, Y., \& Mak, S. (1992). The international transmission of stock market fluctuation between developed markets and the AsianPacific markets. Applied Financial Economics, 2(1), 43-47. http:// dx.doi.org/10.1080/758527545

7. Dekker, A, Sen, K., \& Young, M. (2001). Equity market linkages in the Asia Pacific region: A comparison of the orthogonalized and generalized VAR approaches. Global Finance Journal, 12(1), 1-33. http://dx.doi.org/10.1016/ S1044-0283(01)00025-4

8. Hughen, C., \& Mathew, P. (2009). The efficiency of international information flow: evidence from the ETF and CEF prices. International Review of Financial Analysis, 18(1-2), 4049. http://dx.doi.org/10.1016/j. irfa.2008.12.001

9. Jares, T., \& Lavin, A. (2004). Japan and Hong Kong exchange-traded funds (ETFs): discounts, returns, and trading strategies. Journal of Financial Services Research, 25(1), 57-69. http://dx.doi.org/10.1023/ B:FINA.0000008665.55707.ab.

10. Kolluri B., Machuga, S., \& Wahab, M. (2014). Co-movements of US and Asian equity markets: Evidence from asymmetric and time-varying coefficients. Review of Asian-Pacific Financial Markets and Policies, 17(4), 297315. http://dx.doi.org/10.1142/ S0219091514500210

11. Koutmos, G., \& Booth, G. (1995). Asymmetric volatility transmission in international stock markets. Journal of International Money and Finance, 14(6), 747-762. http://dx.doi.org/10.1016/02615606(95)00031-3

12. Levy, A., \& Lieberman, O. (2013). Overreaction of country ETFs to US market returns: intraday vs. daily horizons and the role of synchronized trading. Journal of Banking \& Finance, 37(5), 14121421. http://dx.doi.org/10.1016/j. jbankfin.2012.03.024

13. Lin, W., Engle, R., \& Ito, T. (1991). Do bulls and bears move across borders? International transmission of stock returns and volatility as the world turns (Working Paper No. 3911). National Bureau of Economic Research.
14. Liu, Y. A., \& Pan, M. (1997). Mean and volatility spillover effects in the U.S. and Pacific-Basin stock markets. Multinational Finance Journal, 1(1), 47-62. Retrieved from https://papers.ssrn.com/sol3/ papers.cfm?abstract_id $=2631572$

15. Marszk, A., Lechman, E., \& Kato, Y. The Emergence of ETFs in Asia Pacific. Springer Nature, Switzerland. http://dx.doi. org/10.1007/978-3-030-12752-7

16. Panton, D, P Lessig, \& Joy, O. (1976). Comovement of international equity markets: a taxonomic approach. Journal of Financial and Quantitative Analysis, 11(3), 415-432. https:// doi.org/10.2307/2330417

17. Pennathur, A., Delcoure, N., \& Anderson, D. (2002). Diversification benefits of IShares and closed-end country funds. Journal of Financial Research, 25(4), 541-557. http://dx.doi. org/10.1111/1475-6803.00036

18. Wei, K. C., Liu, Y., Yang, C., \& Chaung, G. (1995). Volatility and price change spillover effects across the developed and emerging markets. Pacific-Basin Finance Journal, 3(1), 113-136. https://doi.org/10.1016/0927538X(94)00029-7 


\section{APPENDIX A}

Table A1. 2011-2015 daily return impact of S\&P 500 changes on foreign index, ETF and CEF returns

\begin{tabular}{|c|c|c|c|c|c|c|c|c|c|c|c|c|c|c|c|c|}
\hline & \multicolumn{4}{|c|}{ A: Index ${ }_{t+1}=f($ S\&P 500 $)$} & \multicolumn{6}{|c|}{ B: $\mathbf{E T F}_{t}=f\left(\mathbf{S} \& \mathbf{P} 500,{ }_{t}\right.$, Index $\left._{t}\right)$} & \multicolumn{6}{|c|}{ C: CEF $_{t}=f\left(\right.$ S\&P $500,{ }_{t}$ Index $)$} \\
\hline \multirow[t]{3}{*}{ Japan } & \multicolumn{4}{|c|}{ Index: N225 } & \multicolumn{6}{|c|}{ ETF: EWJ } & \multicolumn{6}{|c|}{ CE: JEQ } \\
\hline & $\begin{array}{l}\text { S\&P } \\
500\end{array}$ & & & & S\&P 500 & & N225 & & & & S\&P 500 & & N225 & & & \\
\hline & Coeff. & t-stat & $R^{2}$ & $\mathbf{N}$ & Coeff. & $t$-stat & Coeff. & $t$-stat & $R^{2}$ & $\mathbf{N}$ & Coeff. & $t$-stat & Coeff. & t-stat & $R^{2}$ & $\mathbf{N}$ \\
\hline All changes & 0.67 & 18.77 & 0.23 & 1201 & 0.81 & 36.68 & 0.28 & 17.6 & 0.6 & 1252 & 0.58 & 24.44 & 0.35 & 20.37 & 0.48 & 1252 \\
\hline Changes $\leq-1 \%$ & 0.55 & 3.97 & 0.11 & 132 & 0.84 & 8.44 & 0.11 & 2.51 & 0.4 & 135 & 0.94 & 9.71 & 0.19 & 4.19 & 0.49 & 135 \\
\hline \multirow[t]{3}{*}{ South Korea } & \multicolumn{4}{|c|}{ Index: KS11 } & \multicolumn{6}{|c|}{ ETF: EWY } & \multicolumn{6}{|c|}{ CEF: KF } \\
\hline & $\begin{array}{l}\text { S\&P } \\
500\end{array}$ & & & & S\&P 500 & & KS11 & & & & S\&P 500 & & KS11 & & & \\
\hline & Coeff. & t-stat & $R^{2}$ & $\mathbf{N}$ & Coeff. & t-stat & Coeff. & t-stat & $R^{2}$ & $\mathbf{N}$ & Coeff. & $t$-stat & Coeff. & t-stat & $R^{2}$ & $\mathbf{N}$ \\
\hline All changes & 0.48 & 17.72 & 0.21 & 1204 & 1.00 & 42.67 & 0.55 & 24.85 & 0.71 & 1258 & 0.71 & 31.07 & 0.56 & 25.93 & 0.62 & 1258 \\
\hline Changes $\leq-1 \%$ & .68 & 5.18 & 0.17 & 129 & 1.12 & 9.98 & 0.49 & 6.35 & 0.61 & 136 & 1.01 & 9.32 & 0.46 & 6.21 & 0.59 & 136 \\
\hline \multirow[t]{3}{*}{ Australia } & \multicolumn{4}{|c|}{ Index: AORD } & \multicolumn{6}{|c|}{ ETF:EWA } & \multicolumn{6}{|c|}{ CEF: IAF } \\
\hline & $\begin{array}{l}\text { S\&P } \\
500\end{array}$ & & & & S\&P 500 & & AORD & & & & S\&P 500 & & AORD & & & \\
\hline & Coeff. & t-stat & $R^{2}$ & $\mathbf{N}$ & Coeff. & $t$-stat & Coeff. & $t$-stat & $R^{2}$ & $\mathbf{N}$ & Coeff. & t-stat & Coeff. & t-stat & $R^{2}$ & $\mathbf{N}$ \\
\hline All changes & 0.48 & 21.69 & 0.28 & 1235 & 1.07 & 46.74 & 0.52 & 21.36 & 0.72 & 1258 & 0.75 & 28.67 & 0.56 & 19.89 & 0.55 & 1258 \\
\hline Changes $\leq-1 \%$ & 0.26 & 2.47 & 0.04 & 134 & 1.22 & 11.1 & 0.52 & 6.16 & 0.62 & 136 & 0.93 & 7.63 & 0.64 & 6.92 & 0.52 & 136 \\
\hline \multirow[t]{3}{*}{ Taiwan } & \multicolumn{4}{|c|}{ Index: TWII } & \multicolumn{6}{|c|}{ ETF:EWT } & \multicolumn{6}{|c|}{ CEF: TWN } \\
\hline & $\begin{array}{l}\text { S\&P } \\
500\end{array}$ & & & & S\&P 500 & & TWII & & & & S\&P 500 & & TWII & & & \\
\hline & Coeff. & t-stat & $R^{2}$ & $\mathbf{N}$ & Coeff. & $t$-stat & Coeff. & $t$-stat & $R^{2}$ & N & Coeff. & $t$-stat & Coeff. & t-stat & $R^{2}$ & $\mathbf{N}$ \\
\hline All changes & 0.42 & 15.98 & 0.18 & 1199 & 0.83 & 41.85 & 0.6 & 30.12 & 0.73 & 1258 & 0.61 & 25.07 & 0.51 & 21.09 & 0.52 & 1258 \\
\hline Changes $\leq-1 \%$ & 0.46 & 3.66 & 0.1 & 127 & 0.71 & 7.73 & 0.52 & 8.88 & 0.6 & 136 & 0.74 & 6.88 & 0.46 & 6.81 & 0.51 & 136 \\
\hline \multirow[t]{3}{*}{ Singapore } & \multicolumn{4}{|c|}{ Index: STI } & \multicolumn{6}{|c|}{ ETF: EWS } & \multicolumn{6}{|c|}{ CEF: SGF } \\
\hline & $\begin{array}{l}\text { S\&P } \\
500\end{array}$ & & & & S\&P 500 & & STI & & & & S\&P 500 & & STI & & & \\
\hline & Coeff. & t-stat & $R^{2}$ & $\mathbf{N}$ & Coeff. & $t$-stat & Coeff. & $t$-stat & $R^{2}$ & N & Coeff. & t-stat & Coeff. & $t$-stat & $R^{2}$ & $\mathbf{N}$ \\
\hline All changes & 0.36 & 16.72 & 0.19 & 1217 & 0.75 & 41.00 & 0.58 & 25.61 & 0.72 & 1258 & 0.6 & 28.71 & 0.53 & 20.38 & 0.58 & 1258 \\
\hline Changes $\leq-1 \%$ & 53 & 5.07 & 0.17 & 132 & 0.87 & 5.71 & 0.32 & 4.93 & 0.36 & 136 & 0.65 & 7.37 & 0.64 & 8.93 & 0.63 & 136 \\
\hline China & & Index: S & SSEC & & & & ETF: MC & $\mathrm{CHI}$ & & & & & CEF: CA & & & \\
\hline & $\begin{array}{l}\text { S\&P } \\
500 \\
\end{array}$ & & & & S\&P 500 & & SSEC & & & & S\&P 500 & & SSEC & & & \\
\hline & Coeff. & $t$-stat & $R^{2}$ & $\mathbf{N}$ & Coeff. & $t$-stat & Coeff. & $t$-stat & $R^{2}$ & $\mathbf{N}$ & Coeff. & $t$-stat & Coeff. & $t$-stat & $R^{2}$ & $\mathbf{N}$ \\
\hline All changes & 0.27 & 6.13 & 0.03 & 1163 & 0.93 & 4.36 & 0.29 & 2.02 & 0.02 & 1258 & 0.79 & 22.08 & 0.74 & 31.01 & 0.56 & 1258 \\
\hline Changes $\leq-1 \%$ & 0.33 & 1.67 & 0.02 & 124 & 0.81 & 5.71 & 0.32 & 4.93 & 0.36 & 136 & 0.80 & 5.42 & 0.54 & 8.07 & 0.47 & 136 \\
\hline Indonesia & & Index: J & JKSE & & & & ETF: EIL & DO & & & & & CEF: If & & & \\
\hline & $\begin{array}{l}\text { S\&P } \\
500\end{array}$ & & & & S\&P 500 & & JKSE & & & & S\&P 500 & & JKSE & & & \\
\hline & Coeff. & t-stat & $R^{2}$ & $\mathbf{N}$ & Coeff. & $t$-stat & Coeff. & $t$-stat & $R^{2}$ & $\mathbf{N}$ & Coeff. & $t$-stat & Coeff. & $t$-stat & $R^{2}$ & $\mathbf{N}$ \\
\hline All changes & 0.48 & 15.16 & 0.16 & 1190 & 1.07 & 32.1 & 0.84 & 29.26 & 0.64 & 1258 & 0.71 & 26.95 & 0.52 & 22.95 & 0.54 & 1258 \\
\hline Changes $\leq-1 \%$ & 0.60 & 3.84 & 0.11 & 127 & 0.74 & 6.39 & 0.83 & 13.22 & 0.67 & 136 & 0.79 & 7.62 & 0.47 & 8.35 & 0.55 & 136 \\
\hline
\end{tabular}


Table A2. Determinants of U.S. based Pacific Basin equity investment company returns - 2011-2015 (S\&P 500 return $\leq-1 \%)$

\begin{tabular}{|c|c|c|c|c|c|c|c|c|c|c|}
\hline \multirow{3}{*}{$\begin{array}{c}\text { Country } \\
\text { Japan }\end{array}$} & \multirow{2}{*}{\multicolumn{2}{|c|}{$\frac{\text { Investment Company }}{\text { (Dependent variable) }}$}} & \multirow{2}{*}{\multicolumn{6}{|c|}{ Explanatory variables/regression coefficients }} & \multirow{3}{*}{$\mathbf{R}^{2}$} & \multirow{3}{*}{$\mathbf{N}$} \\
\hline & & & & & & & & & & \\
\hline & \multirow[t]{2}{*}{ ETF: } & \multirow[t]{2}{*}{ EWJ $_{t+1}$} & $\operatorname{S\& P} 500_{t+1}$ & $(t$-stat) & $\mathbf{N} 225_{t+1}$ & $(t$-stat) & $E W J_{t}-N 225_{t+1}$ & (t-stat) & & \\
\hline & & & 0.77 & 13.03 & 0.02 & 0.2 & -0.28 & -4.3 & 0.65 & 129 \\
\hline & CEF: & $\mathrm{JEQ}_{t+1}$ & $\operatorname{S} \& P 500_{t+1}$ & $(t$-stat) & $\mathbf{N}_{225_{t+1}}$ & (t-stat) & $\mathrm{JEQ}_{t}-\mathrm{N}^{225_{t+1}}$ & (t-stat) & & \\
\hline & & & 0.61 & 8.49 & 0.02 & 0.21 & -0.23 & -3.15 & 0.46 & 129 \\
\hline \multirow[t]{4}{*}{ South Korea } & ETF: & $\mathrm{EWY}_{t+1}$ & $\operatorname{S\& P} 500_{t+1}$ & (t-stat) & $\mathrm{KS11}_{t+1}$ & (t-stat) & $E W Y_{t}-K S 11_{t+1}$ & (t-stat) & & \\
\hline & & & 0.90 & 12.8 & 0.30 & 4.08 & -0.27 & -8.96 & 0.69 & 126 \\
\hline & CEF: & $\mathrm{KF}_{t+1}$ & $\operatorname{S\& P} 500_{t+1}$ & (t-stat) & $\mathrm{KS11}_{t+1}$ & (t-stat) & $\mathrm{KF}_{t}-\mathrm{KS} 1_{t+1}$ & (t-stat) & & \\
\hline & & & 0.69 & 11.04 & 0.23 & 3.34 & -0.22 & -3.42 & 0.63 & 126 \\
\hline \multirow[t]{4}{*}{ Australia } & ETF: & EWA $_{t+1}$ & $\operatorname{S\& P} 500_{t+1}$ & $(t$-stat) & $\operatorname{AORD}_{t+1}$ & (t-stat) & $\mathrm{EWA}_{t}-\mathrm{AORD}_{t+1}$ & $(t$-stat) & & \\
\hline & & & 0.98 & 16.46 & 0.49 & 5.65 & -0.30 & -6.28 & 0.8 & 131 \\
\hline & CEF: & $\mathrm{IAF}_{t+1}$ & $\operatorname{S\& P} 500_{t+1}$ & $(t$-stat) & $\operatorname{AORD}_{t+1}$ & $(t$-stat) & $\mathrm{IAF}_{t}-\mathrm{AORD}_{t+1}$ & (t-stat) & & \\
\hline & & & 1.00 & 15.82 & 0.53 & 5.8 & -0.24 & -4.7 & 0.78 & 131 \\
\hline \multirow[t]{4}{*}{ Taiwan } & ETF: & $\mathrm{EWT}_{t+1}$ & S\&P $500_{t+1}$ & (t-stat) & $\mathrm{TWII}_{t+1}$ & (t-stat) & $\mathrm{EWT}_{t}-\mathrm{TWII}_{t+1}$ & (t-stat) & & \\
\hline & & & 0.81 & 14.31 & 0.38 & 5.15 & -0.22 & -3.76 & 0.76 & 123 \\
\hline & CEF: & $\mathrm{TWN}_{t+1}$ & $\operatorname{S} \& P 500_{t+1}$ & (t-stat) & TWII $_{t+1}$ & (t-stat) & $\mathrm{TWN}_{t}-\mathrm{TWII}_{t+1}$ & (t-stat) & & \\
\hline & & & 0.63 & 9.88 & 0.30 & 3.52 & -0.27 & -4.34 & 0.65 & 123 \\
\hline \multirow[t]{4}{*}{ Singapore } & ETF: & EWS $_{t+1}$ & $S \& P 500_{t+1}$ & (t-stat) & $\mathrm{STI}_{t+1}$ & (t-stat) & $\mathrm{EWS}_{t}-\mathrm{STI}_{t+1}$ & (t-stat) & & \\
\hline & & & 0.69 & 14.82 & 0.44 & 6.12 & -0.23 & -4.7 & 0.76 & 130 \\
\hline & CEF: & $\mathrm{SGF}_{t+1}$ & $\operatorname{S\& P} 500_{t+1}$ & $(t$-stat) & $\mathrm{STI}_{t+1}$ & (t-stat) & $\mathrm{SGF}_{t}-\mathrm{STI}_{t+1}$ & $(t$-stat) & & \\
\hline & & & 0.55 & 10.72 & 0.48 & 5.63 & -0.10 & -1.68 & 0.64 & 130 \\
\hline \multirow[t]{4}{*}{ China } & ETF: & $\mathrm{MCHI}_{t+1}$ & $S \& P 500_{t+1}$ & (t-stat) & SSEC $_{t+1}$ & (t-stat) & $\mathrm{MICHI}_{t}-\mathrm{SSEC}_{t+1}$ & (t-stat) & & \\
\hline & & & 0.8 & 8.9 & 0.14 & 1.45 & -0.23 & -3.2 & 0.57 & 121 \\
\hline & CEF: & $\mathrm{CAF}_{t+1}$ & $\operatorname{S\& P} 500_{t+1}$ & (t-stat) & SSEC $_{t+1}$ & (t-stat) & $\mathrm{CAF}_{t}-\mathrm{SSEC}_{t+1}$ & (t-stat) & & \\
\hline & & & 0.61 & 6.42 & 0.60 & 7.07 & -0.35 & -5.23 & 0.72 & 121 \\
\hline \multirow[t]{4}{*}{ Indonesia } & ETF: & EIDO $_{t+1}$ & $\operatorname{S\& P} 500_{t+1}$ & (t-stat) & $\mathrm{JKSE}_{t+1}$ & (t-stat) & EIDOt $-J K S E_{t+1}$ & (t-stat) & & \\
\hline & & & 1.12 & 13.21 & 0.72 & 8.19 & -0.27 & -4.37 & 0.78 & 126 \\
\hline & CEF: & $\mathrm{IF}_{t+1}$ & $\operatorname{S\& P} 500_{t+1}$ & (t-stat) & $\mathrm{JKSE}_{t+1}$ & (t-stat) & $\mathrm{IF}_{t}-\mathrm{JKSE}_{t+1}$ & (t-stat) & & \\
\hline & & & 0.73 & 11.6 & 0.27 & 3.75 & -0.26 & -4.52 & 0.71 & 126 \\
\hline
\end{tabular}

